\title{
Use of Stakeholder Focus Groups to Define the Mission and Scope of a new Department of Population Health
}

\author{
William M. Tierney, MD \\ Department of Population Health, Dell Medical School, University of Texas at Austin, Austin, TX, USA.
}

\begin{abstract}
BACKGROUND: The focus and funding of US healthcare is evolving from volume to value-based, and healthcare leaders, managers, payers, and researchers are increasingly focusing on managing populations of patients. Simultaneously, there is increasing interest in getting "upstream" from disease management to promote health and prevent disease. Hence, the term "population health" has both clinical and community-based connotations relevant to the tripartite mission of US medical schools.
\end{abstract}

OBJECTIVE: To seek broad input for the strategic development of the Department of Population Health in a new medical school at a tier 1 research university.

DESIGN: Focus groups with facilitated consensus development.

PARTICIPANTS: Eighty-one persons representing the Dell Medical School and other schools at the University of Texas at Austin, city/county government, community nonprofit organizations, and faculty from other local university schools along with selected national academic leaders.

APPROACH: Focus groups with subsequent consensus development of emphases identified premeeting by participants by e-mail exchanges.

KEY RESULTS: The resulting departmental strategic plan included scope of work, desired characteristics of leaders, and early impact activities in seven areas of interest: community engagement and health equity, primary care and value-based health, occupational and environment medicine, medical education, health services and community-based research, health informatics and data analysis, and global health.

CONCLUSIONS: Medical schools should have a primary focus in population, most effectively at the departmental level. Engaging relevant academic and community stakeholders is an effective model for developing this emerging discipline in US medical schools.

$\mathrm{J}$ Gen Intern Med 33(7):1069-76

DOI: $10.1007 / \mathrm{s} 11606-018-4403-0$

(c) Society of General Internal Medicine 2018

\section{INTRODUCTION}

Until the past decade or so, medical education in the US focused on developing medical students' skills in diagnosing and treating acute and chronic conditions in individual

Received October 31, 2017

Revised February 26, 2018

Accepted March 7, 2018

Published online April 9, 2018 patients. High-quality care was defined as making an accurate diagnosis, prescribing the best treatment, and preventing specific diseases for patients at risk. More recently, many medical schools have added healthcare delivery science, giving emphasis to healthcare systems and physicians' role in ensuring healthcare's effectiveness and efficiency.

To date, US healthcare has predominantly been mainly "sickness care," focused on fixing what is broken, funded via fee for service that incentivizes utilization. Consequently, the US has mediocre health outcomes yet the world's highest costs ${ }^{1}$ that has driven payers, employers, and governmental agencies to seek substantial changes that incentivize value-based care. ${ }^{2-4}$

The goal is the "triple aim" (improving patients' healthcare experiences and population health while reducing costs and improving population health) by moving upstream from sick care to focus on and ameliorate the clinical, social, behavioral, economic, and structural antecedents of chronic diseases. ${ }^{5}$ An oft-cited report by the University of Wisconsin's Population Health Institute demonstrated that clinical care accounts for only $20 \%$ of healthrelated outcomes (length of life $\times$ quality of life) compared to $40 \%$ by social and economic factors, $30 \%$ by health behaviors, and $10 \%$ by the physical environment. ${ }^{6}$ Yet of more than $\$ 3$ trillion the USA spends annually on health, $95 \%$ goes to healthcare and only $5 \%$ for public health promotion and disease prevention. ${ }^{7}$

Population health is a relatively new concept: before 1990, Medline contains fewer than ten articles per year with "population health" in the title or abstract (Fig. 1). In 2017, there were 1011. Yet the term population health can have both clinical and public health meanings. As shown in Table 1, healthcare providers, practices, health systems, and payers manage specified cohorts of patients. Governments take a wider perspective, focusing on the general health, well-being, and happiness of everyone in their catchment areas, not just patients receiving care.

Medical schools can enhance population health through their tripartite missions of teaching, research, and service, especially in light of CMS' implementing new payment systems incentivizing prevention and cost avoidance. ${ }^{8}$ Yet despite calls for academic medicine to focus on population health, ${ }^{9}$ currently only nine medical schools have established formal departments of population health. (Departments of family and community medicine and departments of preventive medicine have not traditionally adopted a primary population health focus and were not counted among departments of population health. The only existing College of Population Health at Jefferson University was also not 


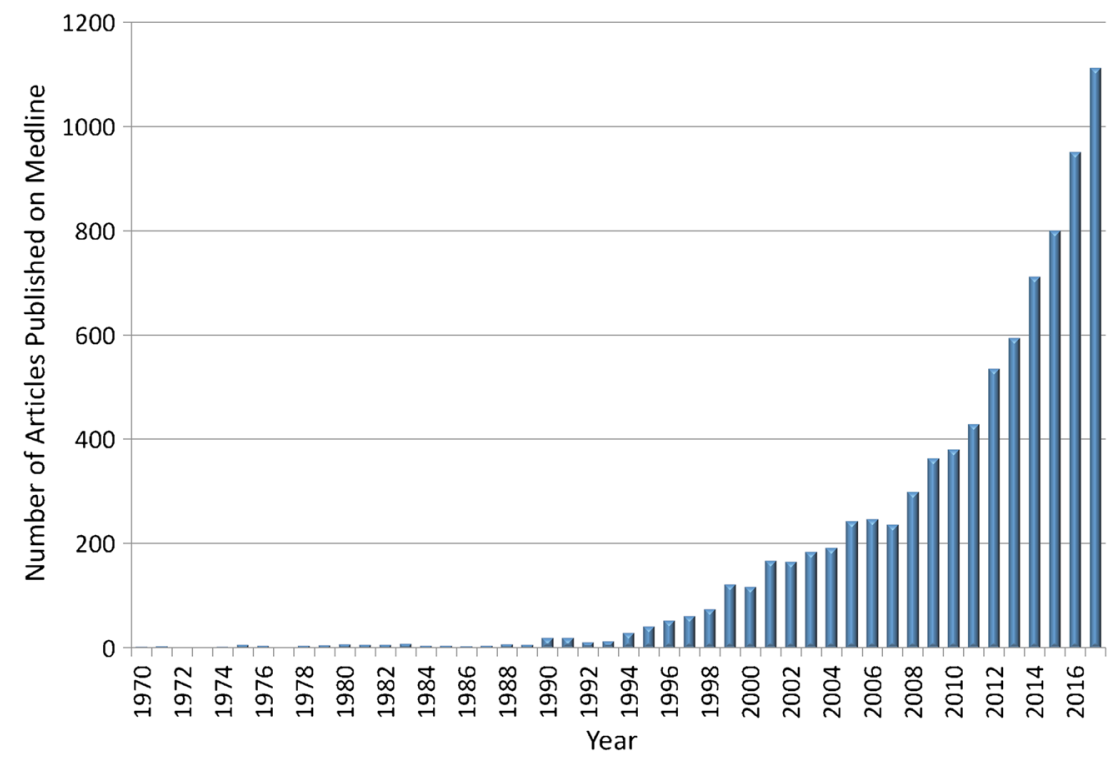

Fig. 1 PubMed citations 1970-2017 with the term "population health" in the title or abstract.

counted because the focus of this report was developing population health departments within medical schools.)

In 2012, the voters of Travis County, Texas, increased their property taxes to create the Dell Medical School in the University of Texas at Austin. In response, the Dean committed to making Austin a model healthy city and established a Department of Population Health to improve the health of Austin and Travis County residents.

There was no model for a population health department: the five existing departments varied widely in their mission, structure, and scope of activities. Therefore, Dell Medical School leaders planned a Population Health Summit where local and national representatives of various community-based and academic stakeholders convened to help craft a department to serve local health needs while helping define this emerging discipline in US medical schools.

\section{METHODS}

Using an iterative, snowball approach, we queried a wide array of stakeholders with interest and relevant expertise in the City of

Table 1 Population Health Perspectives

\begin{tabular}{|c|c|c|}
\hline Perspective & Defined population & Examples of population health management \\
\hline Individual physicians & Patients cared for by each physician & $\begin{array}{l}\text { - Blood pressure control among physician's patients with hypertension } \\
\text { - Glycated hemoglobin among physician's patients with diabetes } \\
\text { - Hospital admissions among physician's patients with heart failure }\end{array}$ \\
\hline Outpatient practices & Patients cared for by all providers & $\begin{array}{l}\text { - Number of patient visits per day } \\
\text { - No-show rates } \\
\text { - Adherence to preventive care guidelines } \\
\text { - Healthcare quality scores } \\
\text { - Patient satisfaction scores } \\
\text { - Blood pressure control by provider among patients with hypertension }\end{array}$ \\
\hline Hospitals & $\begin{array}{l}\text { Patients admitted or seen and released } \\
\text { from emergency departments }\end{array}$ & $\begin{array}{l}\text { - Wait times } \\
\text { - Pength of stay by admitting, discharge diagnosis } \\
\text { - Readmissions within } 30 \text { days by discharge diagnosis } \\
\text { - Adherence to selected treatment or preventive care guidelines } \\
\text { - Patient satisfaction scores }\end{array}$ \\
\hline Health insurers & Persons covered & $\begin{array}{l}\text { - Outpatient visits to primary, specialty care } \\
\text { - Hospitalizations, readmissions within } 30 \text { days } \\
\text { - Charges, payments for care delivered } \\
\text { - Off-formulary prescriptions } \\
\text { - Adherence to selected treatment or preventive care guidelines }\end{array}$ \\
\hline City governments & Persons living in their catchment areas & $\begin{array}{l}\text { - Causes of death } \\
\text { - Numbers of persons with health risk factors, e.g., smoking, obesity } \\
\text { - Numbers of persons engaging in healthy activities, e.g., walking, bicycling } \\
\text { - Number of uninsured and underinsured persons } \\
\text { - Numbers without adequate housing } \\
\text { - Access to healthy food } \\
\text { - Availability of transportation } \\
\text { - Availability and use of green space }\end{array}$ \\
\hline
\end{tabular}


Austin, universities in Texas, and nationally about who to invite to the Population Health Summit. Table 2 shows the categories of stakeholders, number of persons invited (including the chairpersons of all five existing departments of population health in US medical schools), and the number who participated. Appendix Table 3 lists all attendees and their affiliations.

After a welcome from the Dell Medical School's Dean and an introduction by its Chair of Population Health, participants broke into small groups that focused on seven broad themes that were determined before the meeting by iterative in-person and e-mail discussions among meeting participants. Half of the participants were randomly selected to participate in small groups with the focus most consistent with their expertise. The other half of the participants were randomly assigned to groups outside of their areas of expertise to enhance the depth of cross-disciplinary discussions. A trained facilitator led each focus group who instructed participants to (1) describe their focus in detail, which could differ from the original focus group theme, and justify its inclusion as a major division in the Department of Population Health; (2) list desired characteristics of a strong leader; and (3) identify early impactful activities, with relatively short timelines, the department should pursue within that focus area.

At the end of the first day, all Summit participants reconvened; two representatives of each small group summarized its refined focus and implications for population health in Austin and Central Texas. At the beginning of day 2, the focus groups reconvened to confirm their focus definition, refining as necessary and agree on leader characteristics and specific early projects and activities. At day's end, the groups convened to report their recommendations.

Each focus group had two $8 \times 4 \mathrm{ft}$ whiteboards on which participants placed sticky notes with their thoughts concerning the group's focus. The boards were photographed, and each small group facilitator transcribed the notes into an annotated report. Two separate observers took and compared notes from both large group sessions. The resulting large-group and small-group meeting notes were reviewed by the author and summarized in this article.

Table 2 Invitees and Participants in the 2016 Population Health Summit

\begin{tabular}{lll}
\hline \hline Organization & $\begin{array}{l}\text { Number } \\
\text { invited }\end{array}$ & $\begin{array}{l}\text { Number } \\
(\mathbf{\%}) \\
\text { attended }\end{array}$ \\
\hline $\begin{array}{l}\text { Dell Medical School, University of Texas } \\
\text { at Austin }\end{array}$ & 20 & $13(65)$ \\
$\begin{array}{l}\text { Other University of Texas at Austin } \\
\text { schools and colleges }\end{array}$ & 22 & $17(77)$ \\
$\begin{array}{l}\text { Other Texas universities } \\
\begin{array}{l}\text { City, county, and state government } \\
\text { Local healthcare provider organizations }\end{array}\end{array}$ & 7 & $5(71)$ \\
$\begin{array}{l}\text { Local community organizations } \\
\begin{array}{l}\text { Chairs of existing departments of } \\
\text { population health at other US medical }\end{array}\end{array}$ & 17 & $13(100)$ \\
$\begin{array}{l}\text { schools } \\
\text { National experts: health services and } \\
\text { community-based participatory research, } \\
\text { public health, information and data science }\end{array}$ & 5 & $13(93)$ \\
\begin{tabular}{l} 
Total \\
\hline
\end{tabular} & 22 & $10(45)$ \\
\hline
\end{tabular}

\section{RESULTS}

Focus group participants identified seven major themes (divisions) for the Dell Medical School's Department of Population Health: community engagement and health equity, community-centered primary care, occupational medicine, medical education, health services and communitypartnership research, health informatics and data analysis, and global health. Each theme is discussed in detail below.

\section{Community Engagement and Health Equity}

Approximately half of US allopathic medical schools have NIH Clinical and Translational Science Awards that must have community health engagement programs. ${ }^{10}$ However, most of these programs enlist community partners for faculty research. Focus group participants eschewed "parachute research," insisting that community engagement must be an end in itself: creating effective bidirectional communication between the medical school and Austin's communities. This would fulfill the school's teaching, research, and service missions while giving the community a voice in how the school identifies, prioritizes, and meets community health needs. An emphasis was placed on listening to communities members' ideas about collaborative solutions to their health needs. One participant stated, "The experts on what needs fixing in a community and how to fix it are the people who live there."

To do so, the Department of Population Health must understand the historical antecedents to current inequities resulting in Austin's being the third most economically segregated US city. ${ }^{11}$ Consequently, although Austin is among the heathiest cities, ${ }^{12}$ many vulnerable persons have unmet health needs. The best way to enhance community health, therefore, is by focusing on those with inequities and barriers to health.

Participants suggested the Department should convene disparate governmental, civic, and academic organizations whose activities have not been coordinated. Resulting initiatives should be inclusive, transparent, and accountable to the community. The community should have input into measuring what matters, and data supporting these activities should be shared frequently during and after each initiative.

The group acknowledged that Austin's excitement surrounding the new medical school and its population health mission created high expectations that must be managed or could result in disappointment, resentment, and cynicism. This could be accomplished by seeking early collaborative projects with near-term deadlines and publicizing results; being consistently truthful, reliable, and trustworthy; establishing mutually beneficial long-term relationships; and repeatedly seeking and acting upon community input. Being sensitive to power dynamics, meetings should be in community settings at family-friendly times. The Department should establish a community advisory committee to serve a bidirectional communication role: vetting ideas from the medical school for community engagement and health improvement and conveying to the Department and school community residents' needs and potential solutions. 
There was concern that academic turf issues could develop between the Department of Population Health and the UT School of Public Health. Although the overlap in their interests is great - enhancing the health and well-being of community residents - participants felt that overcoming local barriers to health was better served by cooperation and synergy between schools, not competition. Similar thoughts were expressed concerning faculty in UT-Austin schools of Social Work, Nursing, Pharmacy, Business, Engineering, Communications, Liberal Arts, Law, and others with population health interests. As one participant stated, "Population health is a team sport."

\section{Community-Centered Primary Care}

Participants felt healthcare providers should be an important population health resource and should adopt a communitycentered model. ${ }^{13}$ In addition to providing high-value acute and chronic disease management and prevention, this model focuses on proactive partnering with local government and community organizations to overcome social barriers to health. Combining health promotion and disease prevention with value-based primary care would be the most costeffective means to enhance health. But this would require innovative models of healthcare financing so funds that ordinarily pay to treat diseases can pay to prevent them.

Population-focused primary care should be multidisciplinary and include general internal medicine, general pediatrics, family medicine, and relevant specialties (e.g., psychiatry, physical medicine and rehabilitation, and occupational medicine) in a team-based approach. Physician-led teams should include nurses, care managers, social workers, counselors, and community health workers who should engage community residents in their homes and through community-based organizations serving them, e.g., Meals on Wheels and homeless shelters.

Effective community-based primary care should start with capturing granular data on people's health needs at the community, neighborhood, street, and even household level. Starting with data from existing sources, e.g., county departments of public health and electronic health record systems (EHRs), participants urged active collecting of information on health needs from local residents in their homes, beginning with those in proximity to the medical school's primary care practices. More than just documenting health needs, the Department should accept responsibility for helping meeting them and reducing health inequities.

\section{Occupational Medicine}

Employers, especially self-insured, should support health promotion and disease prevention to maintain a healthy, effective workforce. Employees and their families are easy to identify and approach to assess their health needs; participants urged the Department to contract with employers to develop on-site primary care and occupational medicine clinics. Health promotion and disease prevention activities should targeted employees whose jobs put them at risk for injury or illness. The workplace could also actively engage in health promotion through jobsite smoking cessation programs, providing healthy meals for employees and even families, and encouraging (and even financially incentivizing) exercise and stress reduction activities. Participants also suggested partnering with employers and local city officials to enhance employee health, as a ploy to attract new businesses, and with public school systems in promoting children's healthy lifestyles.

\section{Medical Education}

This group reviewed the medical school's nascent curriculum for population health. This included population health principles that preceptors were to weave into case discussions during students' problem-based learning exercises and 4-year precepted professional development discussion groups. These principles included social determinants of health, global health, healthcare and community, epidemiology, and environmental health. The Department of Population Health was charged with developing a Primary Care, Family \& Community Medicine Clerkship where students spend an afternoon a week during their second and third years alternating weeks between their continuity clinics and community engagement or didactic activities. Focus group participants suggested specific venues for primary care and community engagement.

During their third year, Dell Medical students spend 9 months in a discovery activity where they can either obtain a master's degree in one of four possible disciplines or conduct an in-depth project in population health, healthcare redesign, or basic research. Summit participants felt that students interested in population health should partner with existing community organizations and focus on health inequities. Similarly, the school has a program for selected medicine, surgery, and women's health residents who spend 6 months on a population health or healthcare quality improvement project. With these scheduled activities, Summit participants felt the Department should have an educational leader with community-based experience.

From its inception, the Dell Medical School has implemented interprofessional education with UT-Austin's schools of Nursing, Pharmacy, and Social Work, believing that healthcare professionals who practice as teams should be educated together. Participants urged students and faculty from these and other health-related schools to actively collaborate in educational programs and student/resident projects. This would broaden the expertise available to teaching and projects and tighten the bonds between schools with overlapping population health missions.

\section{Health Services and Community-Partnership Research}

Because the Department of Population Health will encompass both health systems and communities, participants demanded rigorous innovation and assessment in both settings. Health services researchers should discover and disseminate models, 
tools, infrastructure, and approaches to enhance the quality, efficiency, and cost-effectiveness of healthcare delivery systems. Tackling precursors to poor health such as poverty, homelessness, loneliness, and lack of education - and seeking structural and policy solutions - should be the purview of community-based researchers in partnership with community members and governmental, civic, and nonprofit organizations serving them. However, some areas of interest such as abuse of tobacco, alcohol, and other substances, violence and trauma, nutrition, and especially health-related inequities should be targeted collaboratively by both types of researchers.

Participants urged investigators to collaborate with faculty in Community Engagement and Public Health, Primary Care, and Occupational Medicine to rigorously assess the impact of innovative approaches to service delivery. Partnering with other UT-Austin schools with overlapping missions and years of experience was strongly encouraged. Participants suggested taking an implementation science approach where (1) clinicians and patients, along with community organizations and the people they serve, identify high priority needs; (2) best practices and innovative approaches are identified and rapidly tested in smaller venues; and (3) successes are disseminated and further evaluated.

Funding for such research will likely come from a variety of traditional and nontraditional sources which must be acceptable to members of promotion and tenure committees. One researcher insisted, "All money is green, and success will depend on us getting credit for funding that doesn't come from NIH." Sustainability of discoveries will depend on substantial funding by those who benefit from such innovations, e.g., city-county-state governments, employers, and healthcare systems.

\section{Health Informatics and Data Analysis}

One can only improve what one measures. In healthcare, the quality, effectiveness, efficiency, safety, and costs of care depend on effective information capture, storage, and communication. Since the Health Information Technology for Economic and Clinical Health (HITECH) Act was passed, more than $95 \%$ of hospitals and $75 \%$ of physicians have installed and routinely use EHRs. ${ }^{14}$ Yet the majority of physicians and other healthcare providers feel their EHR is a barrier to efficient healthcare. ${ }^{15,}{ }^{16}$ Moreover, focus group participants felt that expected improvements in healthcare quality and efficiency expected from EHRs have not materialized. Although the goal of HITECH was enabling patients' data to be accessible wherever they might receive care, issues with data standards and interoperability and trust between health systems have been barriers to sharing health information, adversely affecting healthcare quality and costs.

Participants felt that health informaticists spend most of their time capturing and storing data and too little on getting useful information from them. Therefore, much of the value of healthcare data goes unrealized because such data are difficult to access, often missing or simply wrong, inherently biased as to what data are stored for which patients, and rely significantly - and necessarily - on free text to tell patients' stories. Additionally, patient histories, physical examinations, and diagnostic test results vary over time because patients' providers and health status often change. Moreover, EHRs are enormous-Beth Israel-Deaconess Hospital generates around 80 megabytes of data per patient annually ${ }^{17}$-and disjointed as patients receive care from multiple providers using different, disconnected EHRs. Yet these are the data that physicians and learning health systems must use to effectively care for their patients. One participant noted that public health data are equally diverse but geographic in orientation, often involving variable sampling schemes and providing little individually actionable information.

Several participants stated that there are few standard approaches for using clinical data to identify patient conditions. New, effective methods for visualizing complex, messy healthcare data are badly needed. And connectivity is suboptimal: healthcare providers and community decision-makers need timely, data-based approaches to model risk and design-effective interventions for individuals and populations. Summit participants believed that the Department should be the home of health informatics and advanced analytic methods but draw on the expertise of other UT schools, e.g., for machine learning, keeping the focus on person-centered, valuebased care and reducing health inequities.

The group felt that compiling and sharing data among all health systems in Central Texas was a key immediate need and should include other health-related data that are available in electronic format from nonhealthcare sources such as the US Census Bureau, city and county and state health departments, schools, criminal justice, housing offices, transportation systems, and the EPA. The Polis Center in Indianapolis ${ }^{18}$ and Children's Optimal Health in Austin $^{19}$ are examples of organizations that have compiled such data into databases for identifying and overcoming barriers to health. ${ }^{20}$ Finally, a Central Texas health information exchange should allow people to record data concerning their health conditions and symptoms that affect their comfort and functional capabilities, their risk factors and personal barriers to health, and their health preferences. Data from these and other sources must be secure, readily available, and appropriately used to facilitate comprehensive, collaborative care for acute and chronic illnesses while supporting community-centered health promotion and disease prevention.

\section{Global Health}

This focus group noted that despite the Dell Medical School's having taxpayer support and wanting to help make Austin a 
model healthy city, it should have a global health focus. Participants stressed that because developing countries have limited budgets, healthcare is population focused. Scarce resources usually target high-value interventions such as safe water, antenatal and well-child care, vaccinations, treatment of acute infections and injuries, and treating and preventing locally prevalent, morbid conditions such as childhood diarrhea, tuberculosis, and malaria. Public healthcare venues are supported by ministries of health that manage both healthcare delivery and public health systems which encourage coordination missing in the US.

Moreover, participants pointed out that global health includes local health (which they termed "glocal health"), and many barriers to health and healthcare in developing countries exist in Central Texas, especially rural areas. Hence, foreign approaches to population health could be locally relevant, for example use of community health workers. ${ }^{21}$ To prepare residents to care for the underserved and practice community-based medicine and public health, three quarters of US family medicine residencies offer global health experiences. ${ }^{22}$ Students who have global health experiences also select primary care careers more often ${ }^{23}$ an emphasis of the Dell Medical School.

From a practical standpoint, participants noted that many incoming medical students have had previous international experiences and desire global health opportunities in medical school, especially in areas of need where they can impact lives of vulnerable and underserved persons. These experiences should complement opportunities for students and faculty to care for vulnerable persons in Austin and Central Texas which could help develop compassionate, empathetic, and mindful physicians. Austin and Central Texas also have large and growing Latino and immigrant communities. Therefore, participants encouraged the Department to establish a long-term, mutually beneficial partnership with a Latin American medical school, following the AMPATH model ${ }^{24}$ that emphasizes bilateral educational exchange and building human capacity and infrastructure supporting healthcare and health promotion. Participants stressed that this transnational partnership should be interdisciplinary, involving multiple UT campuses, schools, and departments.

\section{DISCUSSION}

A department of population health should promote both highvalue healthcare and community-based health promotion and disease prevention. To be true to its mission, such departments should engage local academic and community members, leaders, and organizations to establish and follow its mission through effective, long-term partnerships. Community-based collaborative health improvement should therefore go beyond demonstration projects and efficacy studies and establish a catchment area in which to disseminate effective interventions to enhance population health. In addition to diagnosing and treating sick patients, medical schools should train students to identify and overcome community barriers to healthy living.
Effective, engaged population health departments will be eclectic, with foci healthcare delivery, public health, and information science. It is therefore reasonable, if not mandatory, for strategic decision-making to engage other academic disciplines, civic organizations, and local government. Resulting plans will be more widely accepted if the requisite human and organizational infrastructure is readily available and engaged. To succeed, academic population health departments will require new approaches to funding, rewards and benchmarks for faculty advancement, and nontraditional multidisciplinary leadership.

Could existing departments of medicine or family and community medicine do this? Possibly, although it would require that they formally embrace a population health mission. This means going beyond traditional clinical service, teaching, and research to embrace active community engagement and attacking the social, economic, and structural barriers to health.

Is population health different from public health? Apparently so: five of the existing nine departments of population health are in universities with schools of public health. Moreover, the Association of Schools and Programs in Public Health has a Population Health Initiative that is actively defining a population health mission. ${ }^{25}$ Although the definition and role of population health in schools of medicine and public health are evolving, two differences stand out: medical schools include patient management in their population health mission, and community health improvement efforts are more focused on individuals in medical schools vs. policy-focused in public health schools. However, there is - and should be - substantial overlap and synergy in their community health activities.

Establishing a population health focus in US medical schools will require new collaborative game plans and interdisciplinary approaches that break down silos that typify most medical schools. Engaging a variety of stakeholders in defining the mission and scope of new population health departments is a good way to start.

Acknowledgements: The author would like to thank the Design Institute for Health at the Dell Medical School for its help in designing and implementing the qualitative research methods used in this project.

Corresponding Author: William M. Tierney, MD; Department of Population Health Dell Medical School, University of Texas at Austin, Austin, TX, USA (e-mail: tierney@utexas.edu).

Funding Information Funding was provided by the Dell Medical School and the University Federal Credit Union.

Conflict of Interest: The authors declare that they have no conflict of interest.

\section{REFERENCES}

1. Squires D, Anderson C. US health care from a global perspective: spending, use of services, prices, and health in 13 countries. New York, NY: Commonwealth Fund; 2015.

2. Porter ME, Teisberg EO. How physicians can change the future of health care. JAMA 2007; 297:1103-1111. 
3. Burwell SM. Setting value-based payment goals-HHS efforts to improve US health care. N Engl J Med 2015; 372:897-899.

4. Porter ME. Health care 2009: a strategy for health care reform-toward a value-based system. N Engl J Med 2009; 361:109-112.

5. Goldman L, Benjamin G, Kindig D. et al. Advancing the health of communities and populations: a vital direction for health and health care. Available at: https://nam.edu/advancing-the-health-of-communities-and-populations-a-vital-direction-for-health-and-health-care/. Cited April 30, 2017.

6. Booske BC, Athens JK, Kindig DA, Park H, Remington: different perspectives for assigning weights to determinants of health. Madison, University of Wisconsin Population Health Institute, 2010.

7. McGinnis JM, Williams-Russo $\mathbf{P}$, Knickman JR. The case for more active policy attention to health promotion. Health Aff (Millwood) 2002; 21:78-93.

8. Centers for Medicare \& Medicaid Services (CMS), HHS. Medicare Program; Merit-Based Incentive Payment System (MIPS) and Alternative Payment Model (APM) Incentive Under the Physician Fee Schedule, and Criteria for Physician-Focused Payment Models: final rule with comment period. Fed Regist 2016; 81(214):77008-77831.

9. Washington AE, Coye MJ, Boulware LE. Academic health systems third curve: Population health management. JAMA 2016; 315:459-50.

10. National Center for Advancing Translational Science. Clinical and Translational Science Program. Available at: https://ncats.nih.gov/ files/ctsa-factsheet.pdf. Cited April 30, 2017.

11. Florida R, Mellander C. Segregated city: the geography of economic segregation in America's Metros. Toronto: Martin Prosperity Institute, 2017

12. American College of Sports Medicine. ACSM American Fitness Index: 2017 health and community fitness status of the 50 largest metropolitan areas. Available at: www.americanfitnessindex.org/wp-content/uploads / 2014/02/ACSM-AFI-Report-2017.pdf. Cited February 25, 2018.

13. Cantor J, Cohen L, Mikkelson L, Pañares R, Srikantharajah J, Valdovinos E. Community-centered health homes: bridging the gap between health services and community prevention. Oakland: The Prevention Institute, 2011.

14. The Office of the National Coordinator for Health Information Technology. Health IT Dashboard. (http://dashboard.healthit.gov/index.php). Revised June 2015. Cited January 16, 2017.

15. Kellerman AL, Jones SS. What will it take to achieve the as yet unfulfilled promises of health information technology? Health Aff (Millwood) 2013; 32:63-8.

16. Shanafelt TD, Dyrbye LN, Sinsky C, et al. Relationship between clerical burden and characteristics of the electronic environment with physician burnout and professional satisfaction. Mayo Clin Proc 2016; 91:836-848.

17. Halamka JD. Life as a Healthcare CIO. (http://geekdoctor.blogspot.com/ 2011/04/cost-of-storing-patient-records.html). Revised April 2011. Cited January 16, 2017.

18. The Polis Center. Community Informatics. (http://thepoliscenter.iupui. edu/index.php/community-informatics/savi/). Revised January 2017. Cited January 16, 2017.

19. Children's Optimal Health. Visible changes for a healthy future. (http:// cohtx.org). Revised January 2017. Cited January 16, 2017.

20. Morrison D, Lin $\mathbf{Q}$, Wiehe $\mathbf{S}$, et al. Spatial relationships between lead sources and children's blood lead levels in the urban center of Indianapolis (USA). Environ Geochem Health 2013; 35:171-183.

21. Huffman MD, Ojii D, Lloyd-Jones DM. Improving blood pressure control and health systems with community health workers. JAMA 2017; 318:1009-11.

22. Hernandez R, Sevilla Martir JF, Van Durme DJ, et al. Global health in family medicine residency programs: a nationwide survey of US residency directors: a CERA study. Fam Med 2016; 48:532-537.

23. Einterz RM, Kimaiyo S, Mengech HN, et al. Responding to the HIV pandemic: the power of an academic medical partnership. Acad Med 2007; 82:812-818.

24. Association of Schools and Programs of Public Health. ASPPH population health initiative. Available at: http://aspphwb.cmail 19.com/t/i-l-bqlthlzduqdiui-d/. Cited February 25, 2018.

25. Bruno DM, Imperato PJ, Szarek M. The correlation between global health experiences in low-income countries on choice of primary care residencies for graduates of an urban US medical school. J Urban Health 2014; 91:394-402.

\section{APPENDIX 1}

Table 3 Population Health Summit Attendees

\begin{tabular}{ll}
\hline \hline Dell Medical School & \\
Business Affairs & John McCall, MBA \\
Dean & Clay Johnston, MD, PhD \\
Department of Clinical Affairs & Richard Freeman, MD \\
Department of Medical Education & Sue Cox, MD \\
Department of Pediatrics & Steven Abrams, MD \\
Department of Pediatrics & Stephen Pont, MD \\
Department of Surgery and Perioperative & Kevin Bozic, MD, MBA
\end{tabular}

Care

Department of Surgery and Perioperative

Care

Department of Women's Health

Development

Development

Family and Community Medicine

Occupational Medicine

The University of Texas at Austin

Cockrell School of Engineering,

Department of Electrical and Computer

Engineering

College of Liberal Arts, Department of

Sociology

College of Natural Sciences, Department

of Statistics \& Data Sciences

Department of Economics

Department of Sociology, Population

Research Center

LBJ School of Public Affairs

Moody College of Communication

School of Law and Dell Medical School

School of Nursing

School of Nursing

School of Nursing

School of Nursing

School of Public Health, Austin Regional

Campus

School of Social Work

School of Social Work

School of Social Work

School of Social Work

Other Texas universities

Texas A\&M Health Science Center

University of Texas at San Antonio

University of Texas Health Science

Center at Houston

University of Texas Health Science

Center at San Antonio

University of Texas School of Public

Health

City, county, state government

Austin/Travis County Health and Human

Services Department

City of Austin

Central Health

Central Health

CommUnityCare Health Centers

Texas State Senator Kirk Watson's Office

Texas Collaborative for Healthy Mothers and Babies

Local healthcare providers

Austin Regional Clinic

Austin Regional Clinic

Austin Regional Clinic

Seton Healthcare Family

Seton Healthcare Family

Seton Healthcare Family

Seton Healthcare Family

Seton Healthcare Family
Lorrayne Ward, MBA,

MPP

Amy Young, MD

Gail Giebink

Angela Curtis

Dana Sprute, MD, MPH

Edward Bernacki, MD,

$\mathrm{MPH}$

Joydeep Ghosh, PhD

Marc Musick, $\mathrm{PhD}$

Michael Daniels, ScD

Jason Abrevaya, $\mathrm{PhD}$

Debra Umberson, PhD

Todd Olmstead, $\mathrm{PhD}$

Jay Bernhardt, $\mathrm{PhD}$

William Sage, MD, JD

Alexa Stuifbergen, $\mathrm{PhD}$,

RN

Kavita Radhakrishnan,

$\mathrm{PhD}$, MSEE, RN

Richard Brown, $\mathrm{PhD}$

Miyong Kim, $\mathrm{PhD}$

Octavio Martinez, MD

Melissa Smith, MD

Barbara Jones, $\mathrm{PhD}$

Mary Velasquez, $\mathrm{PhD}$

Jack Smith, MD, $\mathrm{PhD}$

Phillip Schnarrs, $\mathrm{PhD}$

Dean Sittig, PhD

Barbara Turner, MD,

MSED

Cheryl Perry, PhD

Philip Huang, MD, MPH

Tim Eubanks

Christie Garbe

Cynthia Valadez

George Miller, MSHA

Sandy Guzman

Divya Patel, PhD

Norman Chenven, MD

Anas Daghestani, MD

Patti Parker

Greg Hartman

Kate Henderson, MHA

Kristi Henderson, DNP

Mark Hernandez, MD

Ray Anderson, PhD, MBA
Steve Kelder, PhD, MPH 
Table 3. (continued)

\begin{tabular}{|c|c|}
\hline Seton Healthcare Family & Ryan Leslie, $\mathrm{PhD}$ \\
\hline Seton Healthcare Family & Shelley Szucs, MBA \\
\hline Seton Healthcare Family & Kari Wholf, MD \\
\hline SW Provider Accountable Care & Kevin Spencer, MD \\
\hline \multirow{2}{*}{\multicolumn{2}{|c|}{$\begin{array}{l}\text { Organization } \\
\text { Local and regional community organizations }\end{array}$}} \\
\hline & \\
\hline $\begin{array}{l}\text { Alliance for African Health in Central } \\
\text { Texas }\end{array}$ & Marva Overton, MBA \\
\hline Children's Optimal Health & Maureen Britton \\
\hline Ending Community Homelessness & Ann Howard, JD, MPA \\
\hline \multicolumn{2}{|l|}{ Coalition } \\
\hline Episcopal Health Foundation & Elena Marks, JD, MPH \\
\hline Independent Health, Wellness and & Marva Overton \\
\hline \multicolumn{2}{|l|}{ Fitness Professional } \\
\hline Latino Healthcare Forum & Jill Ramirez \\
\hline Livestrong Foundation & Rebekkah Schear \\
\hline Mama Sana Vibrant Woman & Kellee Coleman \\
\hline Mama Sana/Vibrant Woman & Paula Rojas \\
\hline Michael and Susan Dell Foundation & Aliya Hussaini, MD \\
\hline St. David's Foundation & Becky Pastner, MPAff \\
\hline St. David's Foundation & William Rice, MD \\
\hline Sustainable Food Center & Joy Casnovsky, MPAff \\
\hline Sustainable Food Center & Ronda Rutledge \\
\hline \multicolumn{2}{|c|}{ Chairs of departments of population health at US medical schools } \\
\hline $\begin{array}{l}\text { Northwell Health and Hofstra School of } \\
\text { Medicine }\end{array}$ & Jacqueline Moline, MD \\
\hline NYU School of Medicine & $\begin{array}{l}\text { Marc Gourevitch, MD, } \\
\text { MPH }\end{array}$ \\
\hline University of Wisconsin, Madison & $\begin{array}{l}\text { F. Javier Nieto, MD, PhD, } \\
\text { MPH }\end{array}$ \\
\hline \multicolumn{2}{|l|}{ National experts } \\
\hline $\begin{array}{l}\text { Indiana University School of Medicine } \\
\text { and the Regenstrief Institute, Inc. }\end{array}$ & Christopher Callahan, MD \\
\hline $\begin{array}{l}\text { Indiana University School of Medicine } \\
\text { and the Regenstrief Institute. Inc. }\end{array}$ & Malaz Boustani, MD \\
\hline Northwestern University Feinberg & Abel Kho, MD \\
\hline School of Medicine & \\
\hline Oregon Health and Science University & David Dorr, MD, MS \\
\hline University Of Alabama at Birmingham & Seth Landefeld, MD \\
\hline School of Medicine & \\
\hline $\begin{array}{l}\text { University of Chicago School of } \\
\text { Medicine }\end{array}$ & Marshall Chin, MD, MPH \\
\hline $\begin{array}{l}\text { University of Cincinnati College of } \\
\text { Medicine }\end{array}$ & Joel Tsevat, MD, MPH \\
\hline $\begin{array}{l}\text { University of Georgia College of Public } \\
\text { Health }\end{array}$ & Steve Bellan, PhD, MPH \\
\hline $\begin{array}{l}\text { University of Iowa Carver College of } \\
\text { Medicine }\end{array}$ & Gary Rosenthal, MD \\
\hline $\begin{array}{l}\text { University of North Carolina at Chapel } \\
\text { Hill, Gillings School of Global Public } \\
\text { Health }\end{array}$ & Morris Weinberger, $\mathrm{PhD}$ \\
\hline
\end{tabular}

